\title{
Re-staging surgery in endometrial cancer: an audit on its value
}

\author{
Sanjay Badesara ${ }^{1}$, Ashitha R. Gangadharan ${ }^{2}$, Rambeer Singh ${ }^{3}$, Adarsh Dharmarajan ${ }^{2 *}$
}

\author{
${ }^{1}$ Department of Surgical Oncology, Delhi State Cancer Institute, Delhi, India \\ ${ }^{2}$ Department of Surgical Oncology, Malabar Cancer Centre, Kerala, India \\ ${ }^{3}$ Department of General Surgery, PGIMS, Rohtak, Haryana, India
}

Received: 30 October 2020

Accepted: 04 November 2020

\author{
*Correspondence: \\ Dr. Adarsh Dharmarajan, \\ E-mail: dradarshdharmarajan@gmail.com
}

Copyright: $@$ the author(s), publisher and licensee Medip Academy. This is an open-access article distributed under the terms of the Creative Commons Attribution Non-Commercial License, which permits unrestricted non-commercial use, distribution, and reproduction in any medium, provided the original work is properly cited.

\begin{abstract}
Background: Incomplete surgical staging in carcinoma endometrium is not an uncommon entity in developing world. Proper surgical staging has got a role in prognostication and planning adjuvant treatment. So, an audit was done to assess the extent of upstaging in women with endometrial cancers who were referred to index centre from outside hospitals with incomplete surgical staging.

Methods: It is a retrospective study. The demographic, clinical and treatment details of women with complete data having at-least one follow up after completion surgery were analyzed. Patients who had any other anticancer treatment elsewhere were excluded. The extent of upstaging was studied based on International federation of gynecology and obstetrics (FIGO) 2008 staging.

Results: A total of 88 patients of endometrial cancer were evaluated retrospectively, of which 10 had completion surgery. $10 \%$ of the patients were upstaged according to the FIGO stage (one from IA to IB), while one patient upstaged from IIIA to IVB after slide review by index centre. According to FIGO Grade, $40 \%$ patient upgraded (one upgraded from I to II, three from II to III) while one downgraded from II to I. Recurrence rate was $40 \%$.

Conclusions: Upstaging is seen in $10 \%$ of patient after completion surgery, which requires the necessity of evaluation by gynecologic oncologist selectively. However, larger and multi-centric studies needed to draw definite conclusion. There is a significant discordance in grade and histology after the review at index centre.
\end{abstract}

Keywords: Endometrial carcinoma, Upstaging, Restaging surgery, Completion surgery

\section{INTRODUCTION}

Endometrial cancer is the most common gynecologic malignancy in the developed world with incidence of $1.28 \%$ annually making it third most common gynecologic malignancy after cervix and ovary. ${ }^{1,2}$ Out of all hystrectromies done for benign conditions $0.3-3 \%$ have endometrial malignancy on final histopathology. ${ }^{3}$ Endometrial cancer is classically thought to spread in a stepwise manner with invasion into the myometrium followed by metastasis to the regional lymph nodes and ultimately systemic spread. ${ }^{4}$ The most important prognostic factors for endometrial cancer is the disease stage and the lymph nodes metastasis. ${ }^{5}$ There is a disagreement regarding lymph node dissection in the management of low risk disease. Agar et al, advocated a single procedure including lymphadenectomy also to reduce that morbidity. ${ }^{6}$ The potential benefits of lymph node dissection must be weighed against the intraoperative and post-operative risks.

Helpman et al reported the results of 1329 consecutive patients during 10-year period. Of 255 patients whose biopsies were grade I (G I) adenocarcinoma, 45 (18\%) were upgraded to grade II (G II) on final pathology, 6 (2\%) were upgraded to grade III (G III) and $5(2 \%)$ were final changed to non-endometrioid high-grade histology, in grade II, $10 \%$ tumors (12/125) while grade III, $24 \%$ had change in histopathology from endometeroid to nonendometroid, in this study outside hospitals slides were not 
reviewed at index centre. ${ }^{7}$ Though recommended as a part of the surgical staging, Positive peritoneal cytology is not included in staging of endometrial carcinoma. ${ }^{8}$ Pooled analysis of 926 patients of PORTEC 1 and two trials showed that lymphovascular space invasion is the most important predictor of recurrence (pelvic and distant) and overall survival while stage I tumors have low lymphovascular space invasion. ${ }^{9}$

There have been studies regarding nodal metastasis in both low and high-risk endometrial cancer but there is scarce data on upstaging. So, the current study was aimed to study upstaging and lymph node positivity.

\section{METHODS}

This was retrospective observational study done at a tertiary cancer care centre in South India, on women who underwent completion surgery for endometrial cancer from January 2015 to March 2018. Institutional review board approval was taken at the onset of the study. Completion surgery is done in patients of endometrial cancers who underwent incomplete primary surgery from outside hospitals and were referred there. Inclusion criteria were women who underwent completion surgery during study period and had completed at least one follow-up after completion treatment. Exclusion criteria were women who had history of radiation or chemotherapy treatment elsewhere before completion surgery.

The demographic, clinical and treatment details of all the subjects were collected from the medical record department. All patients initial histopathology was reviewed by onco-pathologists at the index centre. Then the upstaging and lymph node positivity of endometrial cancer was done by International federation of gynecology and obstetrics (FIGO) classification of cancer endometrium 2008 along with baseline Computed tomography (CT) scan and histopathology.

\section{Statistical analysis}

Data was entered in Microsoft excel sheet. Descriptive and inferential statistics was used to analyze the data. The data were expressed in terms of number and percentages. The statistical analysis was done using IBM Statistical package for social sciences (SPSS) version 23 statistics software.

\section{RESULTS}

Database of 88 patients were studied during the study period which met inclusion and exclusion criteria, out of which ten patients had indication and underwent completion surgery. Patients who underwent completion surgery, majority were in the age group of 51-60 years (50\%). 20\% had diabetes mellitus and 30\% had hypertension as co-morbidity.

Average hospital stay was about $7 \pm 1.7$ days and mean interval between completion surgery and adjuvant treatment was $31.33 \pm 8.41$ days while mean Interval between first surgery and adjuvant treatment 100.6 \pm 22.95 days. Complications included myocardial infarction (grade IVA), burst abdomen (grade IIIB) and lymph edema (grade I), one each. ${ }^{10}$ Nine patients required radiotherapy of which eight received while only one out of four who required adjuvant chemotherapy received (64\% of required treatment actually received).

Table 1: Socio-demographic and clinical profile of patients who underwent completion surgery $(n=10)$.

\begin{tabular}{|lll|}
\hline \multirow{2}{*}{ Characteristic (in years) } & & Number \\
\cline { 2 - 3 } & $41-50$ & $2(20 \%)$ \\
\cline { 2 - 3 } & $51-60$ & $5(50 \%)$ \\
\hline Comorbidity & $\begin{array}{l}\text { Diabetes } \\
\text { mellitus }\end{array}$ & $2(20 \%)$ \\
\cline { 2 - 3 } & Hypertension & $3(30 \%)$ \\
\cline { 2 - 3 } & None & $5(50 \%)$ \\
\hline Average hospital stay & $7 \pm 1.7$ days \\
\hline $\begin{array}{l}\text { Mean interval between } \\
\text { completion surgery and } \\
\text { adjuvant } \\
\text { treatment }\end{array}$ & $31.33 \pm 8.41$ days \\
\hline $\begin{array}{l}\text { Interval between first surgery } \\
\text { and adjuvant treatment }\end{array}$ & $100.6 \pm 22.95$ days \\
\hline $\begin{array}{l}\text { Median follow } \\
\text { up period }\end{array}$ & $\begin{array}{l}13.5 \text { months (4.6- } \\
35.9 \text { months) }\end{array}$ \\
\hline $\begin{array}{l}\text { Complication } \\
\text { (morbidity } \\
\text { grade) }\end{array}$ & $\begin{array}{l}\text { Myocardial } \\
\text { infarction }\end{array}$ & 1 (grade 4a) \\
\cline { 2 - 3 } & Burst abdomen & 1 (grade iiib) \\
\cline { 2 - 3 } $\begin{array}{l}\text { Ldjuvant } \\
\text { radiotherapy }\end{array}$ & Requirement-9 & Received -8 \\
\hline $\begin{array}{l}\text { Adjuvant } \\
\text { chemotherapy }\end{array}$ & Requirement-4 & Received -1 \\
\hline
\end{tabular}

According to FIGO stage- one patient (endometroid carcinoma) upstaged from IA to IB while one (malignant mixed mullerian tumor (MMMT)) from IIIA to IVB upstaged during slide review, while according to FIGO grade, one patient (endometroid carcinoma) upgraded from I to II, three patients ( 2 endometroid carcinoma and 1 serous adenocarcinoma) from II to III and one patient (endometroid carcinoma) from II to I.

Out of the 10 patients who underwent completion surgery, 9 patients had agreement on tissue type of histopathology report from outside and the index centre except for the one where histopathology report from outside reported endometroid carcinoma found to be serous adenocarcinoma at the index centre.

Four out of ten patients had recurrence, 3 had distant recurrences (two inguinal lymph node involvement and one vertebral metastasis), while one patient had local vaginal vault recurrence. Three patients received adjuvant radiation while one received adjuvant chemotherapy. 
Table 2: Upstaging and upgrading according to FIGO stage (2014) and FIGO grade.

\begin{tabular}{|lllllll|}
\hline Histopathology & Histopathology & \multicolumn{2}{l}{ FIGO stage } & \multicolumn{2}{l|}{ FIGO grade } & Adjuvant \\
\hline Outside centre & Index centre & $\begin{array}{l}\text { Outside } \\
\text { centre }\end{array}$ & $\begin{array}{l}\text { Index } \\
\text { centre } \\
\text { centre }\end{array}$ & $\begin{array}{l}\text { Index } \\
\text { centre }\end{array}$ & Received \\
\hline Endometroid carcinoma & Endometroid carcinoma & IA & IA & I & I & FU \\
\hline Endometroid carcinoma & Endometroid carcinoma & IA & IB & I & II & RT \\
\hline Endometroid carcinoma & Endometroid carcinoma & IB & IB & II & I & RT \\
\hline Endometroid carcinoma & Endometroid carcinoma & IB & IB & II & II & RT \\
\hline Endometroid carcinoma & Endometroid carcinoma & IB & IB & II & III & RT \\
\hline Endometroid carcinoma & Endometroid carcinoma & IB & IB & II & III & RT \\
\hline Endometroid carcinoma & Serous Adenocarcinoma & IB & IB & II & III & RT \\
\hline Clear cell carcinoma & Clear cell carcinoma & IB & IB & III & III & RT \\
\hline Serous adenocarcinoma & Serous adenocarcinoma & IB & IB & III & III & RT \\
\hline $\begin{array}{l}\text { Malignant mixed } \\
\text { mullerian tumor }\end{array}$ & $\begin{array}{l}\text { Malignant mixed mullerian } \\
\text { tumor }\end{array}$ & IIIA & IVB & III & III & CT \\
\hline
\end{tabular}

RT=Radiotherapy; FU=Follow Up; CT=Chemotherapy.

Table 3: Follow up and recurrence among patients.

\begin{tabular}{|lllllll|}
\hline Histopathology & $\begin{array}{l}\text { Site of } \\
\text { recurrence }\end{array}$ & $\begin{array}{l}\text { Interval between } \\
\text { initial surgery } \\
\text { and adjuvant } \\
\text { (weeks) }\end{array}$ & $\begin{array}{l}\text { Adjuvant } \\
\text { RT } \\
\text { received }\end{array}$ & $\begin{array}{l}\text { Adjuvant } \\
\text { CT } \\
\text { received }\end{array}$ & $\begin{array}{l}\text { DFI } \\
\text { (Months) }\end{array}$ & Palliation \\
\hline MMMT & Vaginal vault & $>12$ & No & Yes & 14 & RT \\
\hline Serous carcinoma & $\begin{array}{l}\text { Inguinal } \\
\text { lymph node }\end{array}$ & $>12$ & Yes & No & 6 & CT \\
\hline Adenocarcinoma & $\begin{array}{l}\text { Vertebral } \\
\text { metastasis }\end{array}$ & 10 & Yes & No & 7 & RT \\
\hline $\begin{array}{l}\text { Serous } \\
\text { adenocarcinoma }\end{array}$ & $\begin{array}{l}\text { Inguinal } \\
\text { lymph node }\end{array}$ & $>12$ & Yes & No & 8 & Opted out \\
\hline
\end{tabular}

MMMT-Malignant Mullerian Mixed Tumour, DFI-Disease Free, RT=Radiotherapy; CT=Chemotherapy.

\section{DISCUSSION}

Incomplete surgical staging in case of endometrial cancers is not a rare entity. It may be due to improper evaluation in preoperative period, lack of precise frozen section or pathology reporting due to less trained pathologist in low middle income countries like India. ${ }^{11}$ Other reasons may be inadequate evaluation of abnormal uterine bleeding in post-menopausal age group and unfortunately malignant final histopathology in patients operated for benign conditions. For better management of patients we have to choose in between restaging with lymphadenectomy or may be omentectomy, follow up with no adjuvant treatment in selected group of patients, adjuvant radiations or chemotherapy or both.

Retrospective analysis of 88 patients were done of which, ten patients underwent completion surgery. Upstaging was present in $10 \%$ of the patients. The rate of upstaging is low as all the stages are taken into consideration and not only apparently early stages. However there is slightly a higher percentage of upstaging by Thomas et al, which was $25 \% .^{12}$ Majority of patients $(50 \%)$ who underwent completion surgery were in the age group of 51-60 years which is in concordance with studied by Thomas et al, where most of patients fall in range of 31-67 years. ${ }^{12}$ This shows that the age group between 51-60 years is prone for endometrial cancer which is also the case in the present study.

In the present study $20 \%$ had diabetes mellitus and $30 \%$ had hypertension as co-morbidity which are the components of metabolic syndrome. These findings are strengthened by the findings of Thomas et al, where $40 \%$ had body mass index (BMI) of more than $30 .{ }^{12}$ Complications included myocardial infarction, burst abdomen and lymph edema (one each) in the present study. While in the other study complications included iliac vein injury and bladder injury. ${ }^{12}$ The difference might be due to multiple factor like general status of the patient and disease progression.

Out of the ten patients who underwent completion surgery, $90 \%$ (9 patients) required radiotherapy after final histopathology reporting, but 8 had indication of adjuvant radiations after slide review, so one patient upgraded in adjuvant radiotherapy group. However adjuvant radiotherapy was received by eight patients $(88.89 \%)$. Adjuvant chemotherapy was required by $40 \%$ of patients after slide review but no change in adjuvant chemotherapy 
patients, out of which only $25 \%$ (one patient) received it, was due to poor compliance (two patients), and long duration of treatment (one patient) despite having acceptable general condition. However in other study $20 \%$ (5 patients) required radiotherapy (vaginal brachytherapy therapy) and 20\% (5 patients) were advised both chemotherapy and radiation. ${ }^{12}$ This difference would be due to age of the patients, final stage, grade and histopathology while consideration for adjuvant treatment.

In the present study, according to FIGO stage (10\%) one (MMMT) from IIIA to IVB) patient upstaged while according to FIGO grade, $40 \%$ patient upgraded (one patient upgraded from I to II, three patients from II to III) while $10 \%$ downgraded (one patient from II to I). While in study by Zhou et al, showed 34.6\% (28/81) of patients had change in tumor grade. $25.9 \%$ on slide review showed upgrading as compared from $8.6 \%$ were downgraded. ${ }^{13}$

Out of the 10 patients who underwent completion surgery, $8(80 \%)$ patients had agreement on histopathology report from outside and the index centre which is in close concordance with other study that showed $75.3 \%$ agreement. ${ }^{12}$ In this study one histopathology report from outside reported endometroid carcinoma and serous adenocarcinoma at the index centre and endometroid adenocarcinoma from $1 \mathrm{~A}$ to $1 \mathrm{~B}$. In the present study, majority of patient $(60 \%)$ had endometroid type of endometrial carcinoma which is the most common type, while other study by Zhou et al (85.2\%) and Thomas et al $(70 \%)$ showed majority of histopathology were endometroid type. ${ }^{12,13}$

In the present study, recurrence rate is $40 \%$. Four patients had recurrence during median follow up period 13.5 months (4.6-35.9 months), of which the woman with MMMT (DFI-14 months) had indication for chemoradiation but opted out for radiations due to lack of compliance. This may be the cause of local (vaginal cuff) recurrence. Two out of four recurrences had serous histopathology, were advised for chemo-radiation therapy and both took only radiation therapy. They had inguinal lymph node recurrences (distant recurrence). One woman with adenocarcinoma had indication for adjuvant radiation therapy. After 7 months she had vertebral recurrence which might be due to adjuvant radiation only treatment, who does not protect distant recurrences and she expired after palliative radiations. The overall recurrence rate was $2 / 20(10 \%)$ patients during the study period of 48 months, and two women died of disease progression in a study by Thomas et al. ${ }^{12}$ A study by Kaewpangchan et al showed vaginal cuff recurrence was $37.5 \%$, while inguinal lymph node and bone recurrence was $4.8 \%$ each. ${ }^{14}$ This discordance in recurrence percentage might be due to the fact that patients did not follow the standard treatment during adjuvant period.

\section{CONCLUSION}

Upstaging is seen in $10 \%$ of patient after completion surgery in carcinoma endometrium which requires the necessity of evaluation by gynaecologic oncologist selectively. However, larger and multi-centric studies are needed to draw definite conclusion. Before completion staging we have to keep in mind, the performance status of patient and whether we are able to change the adjuvant treatment in the patient without adding much morbidity and significant delay in completion of adjuvant treatment. There was a significant discordance in grade and histology after the review at a tertiary centre which raises the requirement of trained onco-pathologist to review the slides. So, re-surgery has a dubious role for delaying the adjuvant treatment and discourages the patients from taking adjuvant treatment, this should be evaluated in large series.

\section{ACKNOWLEDGMENTS}

We acknowledge all participants who consented to be a part of our study and the institution for their kind cooperation in the making of this article and its submission.

\section{Funding: No funding sources}

Conflict of interest: None declared

Ethical approval: The study was approved by the Institutional Ethics Committee

\section{REFERENCES}

1. Kadan Y, Calvino AS, Katz A, Katz S, Moore RG. Predictors for lymph nodes involvement in low risk endometrial cancer. J Obstetr Gynaecol. 2017;37(4):514-8.

2. The Global Cancer Observatory- Globocan 2018.

3. Graebe K, Garcia-Soto A, Aziz M, Valarezo V, Heller $\mathrm{PB}$, Tchabo $\mathrm{N}$ et al. Incidental power morcellation of malignancy: a retrospective cohort study. Gynecol Oncol. 2015;136:274-7.

4. Jorge S, Hou JY, Tergas AI, Burke WM, Huang Y, $\mathrm{Hu} \mathrm{JC}$, et al. Magnitude of risk for nodal metastasis associated with lymphvascular space invasion for endometrial cancer. Gynecol Oncol. 2016;140(3):387-93.

5. Roma AA, Rybicki LA, Barbuto D. Risk factor analysis of recurrence in low-grade endometrialadenocarcinoma. Hum Pathol. 2015;46:1529-39.

6. Agar N, Philippe AC, Bourdel N. Morbidity of pelvic lymphadenectomy and para-aortic lymphadenectomy in endometrial cancer. Bull Cancer. 2015;102:428-35.

7. Helpman L, Kupets R, Covens A, Saad RS, Khalifa MA, Ismiil N, et al. Assessment of endometrial sampling as a predictor of final surgical pathology in endometrial cancer. Br J Cancer. 2014;110(3):609-15. 
8. National Comprehensive Cancer Network. NCCN Clinical Practice Guidelines in Oncology: Uterine Neoplasms. NCCN Guidelines; 2017.

9. Bosse T, Peters EE, Creutzberg CL. Substantial lymph-vascular space invasion (LVSI) is a significant risk factor for recurrence in endometrial cancer-a pooled analysis of PORTEC 1 and 2 trials. Eur J Cancer. 2015;51:1742-50.

10. Katayama H, Kurokawa $Y$, Nakamura K, Ito $H$. Extended Clavien-Dindo classification of surgical complications: Japan Clinical Oncology Group postoperative complications criteria. Surgery Today. 2015;46(6):668-85.

11. Wilson ML, Fleming KA, Kuti MA, Looi LM, Lago $\mathrm{N}, \mathrm{Ru} \mathrm{K}$. Access to pathology and laboratory medicine services: a crucial gap. The Lancet. 2018;391(10133):1927-38.

12. Thomas V, Thomas A, Sebastian A, Chandy R, Peedicayih A. Inadequately Staged Endometrial
Cancer: a Clinical Dilemma. Indian Journal of Surgical Oncology. 2017;9(2):166-70.

13. Zhou Q, Singh SR, Yunzhe L, Mo Z, Huang J. Preoperative Histopathological Grading and Clinical Staging Versus Surgico-Pathological Grading and Surgical Staging in Endometrial Carcinoma Patients: A Single Centre Retrospective Study. Global J Med Res. 2018;18(1):19-28.

14. Kaewpangchan P, Cheewakriangkrai C. Relapse Patterns and Outcomes Following Recurrence of Endometrial Cancer in Northern Thai Women. Asian Pac J Cancer Prev. 2015;16(9):3861-66.

Cite this article as: Badesara $S$, Gangadharan $A R$, Singh R, Dharmarajan A. Re-staging surgery in endometrial cancer: an audit on its value. Int $\mathbf{J}$ Reprod Contracept Obstet Gynecol 2020;9:4898-902. 